\title{
Spatial Metrics based Landscape Structure and Dynamics Assessment for an emerging Indian Megalopolis
}

\author{
Ramachandra T.V ${ }^{1,2,3^{*}}$, Bharath H. Aithal ${ }^{1,2}$, Sreekantha S. ${ }^{1,3}$ \\ ${ }^{1}$ Energy \& Wetlands Research Group, Centre for Ecological Sciences [CES], \\ ${ }^{2}$ Centre for Sustainable Technologies (astra), \\ ${ }^{3}$ Centre for infrastructure, Sustainable Transportation and Urban Planning [CiSTUP], \\ Indian Institute of Science, Bangalore, 560 012, India \\ http://ces.iisc.ernet.in/energy; http://ces.iisc.ernet.in/grass \\ *corresponding author: +91-080-22933099
}

\begin{abstract}
Human-induced land use changes are considered the prime agents of the global environmental changes. Urbanisation and associated growth patterns (urban sprawl) are characteristic of spatial temporal changes that take place at regional levels. Unplanned urbanization and consequent impacts on natural resources including basic amenities has necessitated the investigations of spatial patterns of urbanization. A comprehensive assessment using quantitative methods and methodological understanding using rigorous methods is required to understand the patterns of change that occur as human processes transform the landscapes to help regional land use planners to easily identify, understand the necessary requirement. Tier II cities in India are undergoing rapid changes in recent times and need to be planned to minimize the impacts of unplanned urbanisation. Mysore is one of the rapidly urbanizing traditional regions of Karnataka, India. In this study, an integrated approach of remote sensing and spatial metrics with gradient analysis was used to identify the trends of urban land changes. The spatial and temporal dynamic pattern of the urbanization process of the megalopolis region considering the spatial data for the five decades with $3 \mathrm{~km}$ buffer from the city boundary has been studied, which help in the implementation of location specific mitigation measures.

The time series of gradient analysis through landscape metrics helped in describing, quantifying and monitoring the spatial configuration of urbanization at landscape levels. Results indicated a significant increase of urban built-up area during the last four decades. Landscape metrics indicates the coalescence of urban areas occurred during the rapid urban growth from 2000 to 2009 indicating the clumped growth at the center with simple shapes and dispersed growth in the boundary region with convoluted shapes.
\end{abstract}

Keywords-Landscape Metrics; Urbanisation; Urban Sprawl; Remote sensing; Geoinformatics; Mysore City, India.

\section{INTRODUCTION}

Patterns and processes of globalization and consequent urbanization are the factors influencing contemporary land use trends and also posing challenges for sustainable land uses [9]. Analysis of landscape patterns and dynamics has become the primary objectives of landscape, geographical and ecological studies in recent times. Landscape changes involving large scale deforestation are the primary drivers of the climate change [52], [11] earth dynamics [51]. The spatial patterns of landscape transformation through time are undoubtedly related to changes in land uses [41].Landscape changes are diverse but very often influenced by regional policies [6]. The main driving factors for global environmental changes are been identified as agriculture intensification [17], [19], urbanisation [40] in the context of local policies[24,30,34]. The socio-economic impacts are often determinants of the type of land use within a given region, which in turn affect environmental issues [32], [35]. In order to address these urbanization challenges without compromising the environment values and their local sustainance, land use planning and necessary supporting data are crucial, especially to developing countries under severe environmental and demographic strains [12].

Urbanization is a irreversible process involving changes in vast expanse of land cover with the progressive concentration of human population. Urbanising landscapes will invariably have high population density that might lead to lack of infrastructure and provision of basic facilities. The urban population in India is growing at about $2.3 \%$ per annum with the global urban population increasing from 13\% (220 million in 1900) to $49 \%$ (3.2 billion, in 2005) and is projected to escalate to $60 \%$ (4.9 billion) by 2030 [42]. Population of Mysore is 1 million as per census 2001 compared to 0.653 million (1991).

The increase in urban population is in response to the growth in urban areas due to migration from either rural area or other cities. There are 48 urban agglomerations (Mega cities, Tier I) having a population of more than one million in India (in 2011). Tier 1 cities have reached the saturation level evident from lack of basic amenities, traffic bottlenecks, higher concentrations of pollutants, higher crime rates due to burgeoning population. In this context, well planned Tier 2 cities offer humongous potential with the scope for meeting the basic amenities required. This entails the provision of basic infrastructure (like roads, air and rail connectivity), adequate social infrastructure (such as educational institutions, hospitals, etc.) along with other 
facilities. Modeling and visualization of urban growth based on the historical spatio-temporal data would help in identifying the probable regions of intense urbanization and sprawl.

Urban sprawl implies a sharp imbalance between urban spatial expansion and the underlying population growth [5]. Sprawl of human settlements is a major driving force of land use and land cover changes [3], [16] with detrimental impacts on natural resources and local ecology. Sprawl process entails the growth of the urban area from the urban center towards the periphery of the city municipal jurisdiction. These small pockets in the outskirts lack basic amenities like supply of treated water, electricity and sanitation facilities. Sprawl is associated with high negative impacts and especially the increasing dependency for basic amenities [50], the need for more infrastructure [5], the loss of agricultural and natural land, higher energy consumption, the degradation of peri-urban ecosystems etc., [23], [25], [27]. Understanding the sprawl over past few decades is crucial for the regional administration to handle the population growth and provide basic amenities while ensuring the sustainable management of local natural resources.

The information about the current and historical land cover/land use plays a major role for urban planning and management [54]. Mapping landscapes on temporal scale provide an opportunity to monitor the changes, which is important for natural resource management and sustainable planning activities. In this context, "Density Gradient" with the time series spatial data analysis is potentially useful in measuring urban development [50]. This article presents the temporal land use analysis and adopts the density gradient approach to evaluate and monitor landscape dynamics and further explains the landscape pattern through use of landscape metrics.

Knowledge of the spatio-temporal pattern of the urbanization is important to understand the size and functional changes in the landscape. Spatial metrics were computed to quantify the patterns of urban dynamics, that aid in understanding spatial patterns of various land cover features in the region [33]. Quantifying the landscape pattern and its change is essential for monitoring and assessing the urbanization process and its ecological consequences [31], [20], [27], [46]. Spatial metrics have been widely used to study the structure, dynamic pattern with the underlying social, economic and political processes of urbanization [21], [22], [45], [53]. This has provided useful information for implementing holistic approaches in the regional land-use planning [48]. [1] reviews the spatial characteristics of metropolitan growth including analysis [2], [4], [14], [28] the study of urban landscapes. Applications of landscape metrics include landscape ecology (number of patches, mean patch size, total edge, total edge and mean shape), geographical applications by taking advantage of the properties of these metrics [15], [39], [44] and measurement of ecological sustainability [43].

These studies also confirmed that Spatio-temporal data along with landscape metrics would help in understanding and evaluating the spatio temporal patterns of landscape dynamics required for appropriate management measures.
According to the City Development Plan (CDP), a 20year vision document for Mysore, there has been a $70 \%$ increase in the city's spatial extent since 2001, resulting in the higher degree of sprawl at outskirts. Objectives of this study are to understand and interpret the evolving landscape dynamics through temporal analysis of land use land cover pattern taking $3 \mathrm{~km}$ buffer, through spatial metrics.

\section{STUDY AREA}

Mysore city in Karnataka is one of the tier II cities and the cultural capital of India with a hub of industrial activities. It is designated as the 2nd capital of Karnataka. Mysore city is 128 sq. $\mathrm{km}$ in area and is one of the most preferred destinations for industries including IT hubs other than Bangalore.It is a main trading centre of silk and sandalwood. Mysore district is bounded by Mandya to the northeast, Chamrajnagar to the southeast, Kerala state to the south, Kodagu to the west, and Hassan to the north. It has an area of $128.42 \mathrm{~km}^{2}$ and a population of about 1 million (2001 census). The district lies in the southern Deccan plateau, within the watershed region of Kaveri River, which flows through the northern and eastern parts of the district.

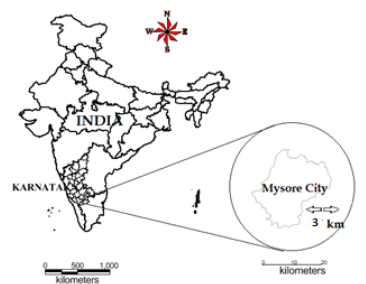

Figure 1. Study Area: Mysore city and $3 \mathrm{~km}$ buffer

III. MATERIALS USED

\begin{tabular}{|c|c|c|}
\hline DATA & Year & Purpose \\
\hline $\begin{array}{c}\text { Landsat Series } \\
\text { MSS(57.5m) }\end{array}$ & 1973 & $\begin{array}{c}\text { Landcover and Land } \\
\text { use analysis }\end{array}$ \\
\hline $\begin{array}{c}\text { Landsat Series TM } \\
(28.5 \mathrm{~m}) \text { and ETM }\end{array}$ & $\begin{array}{c}1989, \\
1999,\end{array}$ & $\begin{array}{c}\text { Landcover and Land } \\
\text { use analysis }\end{array}$ \\
\hline $\begin{array}{c}\text { IRS p6: Liss-4 MX } \\
\text { data (5.6m) }\end{array}$ & 2009 & $\begin{array}{c}\text { Landcover and Land } \\
\text { use analysis }\end{array}$ \\
\hline $\begin{array}{c}\text { Survey of India (SOI) } \\
\text { toposheets of 1:50000 } \\
\text { and 1:250000 scales }\end{array}$ & & $\begin{array}{c}\text { To Generate } \\
\text { boundary and Base } \\
\text { layer maps. }\end{array}$ \\
\hline $\begin{array}{c}\text { Field visit data - } \\
\text { captured using GPS }\end{array}$ & & $\begin{array}{c}\text { For geo-correcting } \\
\text { and generating } \\
\text { validation dataset }\end{array}$ \\
\hline
\end{tabular}

TABLE I. MATERIALS USED IN ANALYSIS

\section{METHOD}

A two-step approach was adopted to chart the direction of the City's development, which includes (i) a normative approach to understand the land use and (ii) a gradient approach of $1 \mathrm{~km}$ radius to understand the pattern of growth during the past 4 decades. Various stages in the data analysis are: 


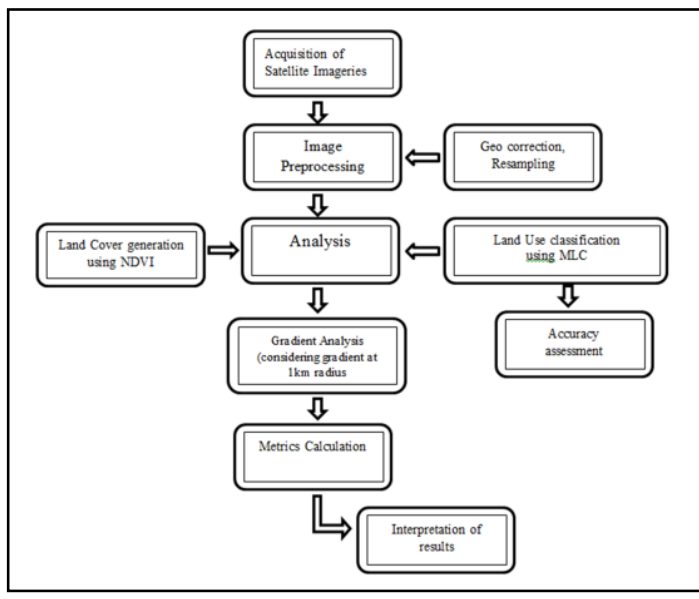

Figure 2. Procedure followed to understand the spatial pattern of landscape change

\section{A. Preprocessing}

The remote sensing data obtained were geo-referenced, rectified and cropped pertaining to the study area. The Landsat satellite 1973 images have a spatial resolution of $57.5 \mathrm{~m} \times 57.5$ $\mathrm{m}$ (nominal resolution) and 1989 - 1999 data of $28.5 \mathrm{~m} \times 28.5$ $\mathrm{m}$ (nominal resolution) were resampled to uniform $30 \mathrm{~m}$ for intra temporal comparisons. Latest data of IRS P6 of spatial resolution $5.6 \mathrm{~m}$ was procured from NRSC, Hyderabad (http://www.nrsc.gov.in).

Vegetation Cover Analysis: Normalized Difference Vegetation index (NDVI) was computed to understand the temporal dynamics of the vegetation cover. NDVI value ranges from values -1 to +1 , where -0.1 and below indicate soil or barren areas of rock, sand, or urban buildup. NDVI of zero indicates the water cover. Moderate values represent low density vegetation ( 0.1 to 0.3$)$ and higher values indicate thick canopy vegetation (0.6 to 0.8$)$.

\section{B. Land use analysis}

Land use categories listed in Table 2 were classified with the training data (field data) using Gaussian maximum likelihood supervised classier. The analysis included generation of False Color Composite (bands - green, red and NIR), which helped in identifying heterogeneous area. Polygons were digitized corresponding to the heterogeneous patches covering about $40 \%$ of the study region and uniformly distributed over the study region.

These training polygons were loaded in pre-calbrated GPS (Global position System). Attribute data (land use types) were collected from the field with the help of GPS corresponding to these polygons. In addition to this, polygons were digitized from Google earth (www.googleearth.com) and Bhuvan (bhuvan.nrsc.gov.in), which were used for classifying latest IRS P6 data. These polygons were overlaid on FCC to supplement the training data for classifying landsat data.

Gaussian maximum likelihood classifier (GMLC) is applied to classify the data using the training data. GMLC uses various classification decisions using probability and cost functions [10] and is proved superior compared to other techniques. Mean and covariance matrix are computed using estimate of maximum likelihood estimator. Estimations of temporal land uses were done through open source GIS (Geographic Information System) - GRASS (Geographic Resource Analysis Support System, http://ces.iisc.ernet.in/grass).

$70 \%$ of field data were used for classifying the satellite data and the balance $30 \%$ were used in validation and accuracy assessment. Thematic layers were generated of classified data corresponding to four land use categories.

Evaluation of the performance of classifiers [36], [37], [13] is done through accuracy assessment techniques of testing the statistical significance of a difference, comparison of kappa coefficients [8], [47] and proportion of correctly allocated classes [12] through computation of confusion matrix. These are most commonly used to demonstrate the effectiveness of the classifiers [8], [7], [29].

Further each zone was divided into concentric circle of incrementing radii of $1 \mathrm{~km}$ (figure 2) from the center of the city for visualising the changes at neighborhood levels. This also helped in identifying the causal factors and the degree of urbanization (in response to the economic, social and political forces) at local levels and visualizing the forms of urban sprawl. The temporal built up density in each circle is monitored through time series analysis.

TABLE I. a LAND USE CATEGORIES

\begin{tabular}{|l|l|}
\hline Land use Class & Land uses included in the class \\
\hline Urban & $\begin{array}{l}\text { This category includes residential area, } \\
\text { industrial area, and all paved surfaces and } \\
\text { mixed pixels having built up area. }\end{array}$ \\
\hline Water bodies & Tanks, Lakes, Reservoirs. \\
\hline Vegetation & Forest, Cropland, nurseries. \\
\hline Others & $\begin{array}{l}\text { Rocks, quarry pits, open ground at } \\
\text { building sites, kaccha roads. }\end{array}$ \\
\hline
\end{tabular}

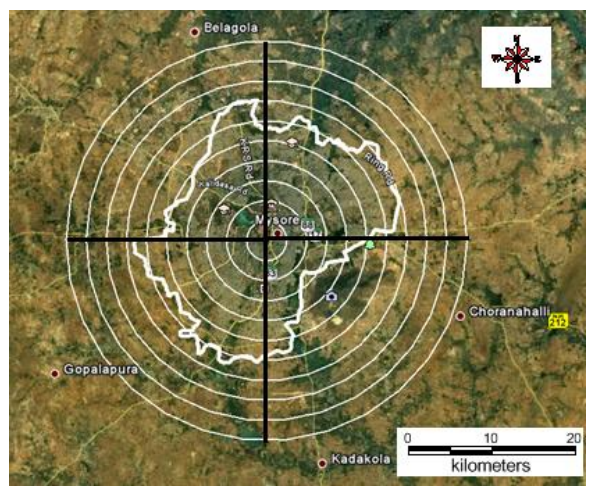

Figure 3. Google earth representation of the study region

\section{Urban sprawl analysis}

Direction-wise Shannon's entropy (Hn) is computed (equation 1) to understand the extent of growth: compact or divergent [26], [49], [38]. This provides an insight into the development (clumped or disaggregated) with respect to the 
geographical parameters across ' $n$ ' concentric regions in the respective zones.

$$
\mathrm{Hn}=-\sum_{\mathrm{i}=1}^{\mathrm{n}} \mathrm{Pi} \log (\mathrm{Pi})
$$

Where $\mathrm{Pi}$ is the proportion of the built-up in the $\mathrm{i}^{\text {th }}$ concentric circle and $\mathrm{n}$ is the number of circles/local regions in the particular direction. Shannon's Entropy values ranges from zero (maximally concentrated) to $\log \mathrm{n}$ (dispersed growth).

\section{Spatial pattern analysis}

Landscape metrics provide quantitative description of the composition and configuration of urban landscape. These metrics were computed for each circle, zonewise using classified landuse data at the landscape level with the help of FRAGSTATS [34].

Urban dynamics is characterised by 11 spatial metrics chosen based on complexity, centrality and density criteria. The metrics include the patch area, edge/border, shape, epoch/contagion/ dispersion and are listed in Table II.

\section{RESULTS \& DISCUSSION}

\section{1) Land use Land Cover analysis:}

a) Vegetation cover analysis: Vegetation cover of the study area assessed through NDVI (Figure 3), shows that area under vegetation has declined to $9.24 \%$ (2009) from $51.09 \%$ (1973). Temporal NDVI values are listed in Table III.

b) Land use analysis: Land use assessed for the period 1973 to 2009 using Gaussian maximum likelihood classifier is listed Table IV and the same is depicted in figure 4. The overall accuracy of the classification ranges from $75 \%$ (1973), $79 \%$ (1989), 83\% (1999) to 88\% (2009) respectively. Kappa statistics and overall accuracy was calculated and is as listed in Table V.

c) There has been a significant increase in built-up area during the last decade evident from $514 \%$ increase in urban area. Other category also had an enormous increase and covers $166 \%$ of the land use. Consequent to these, vegetation cover has declined drastically during the past four decades. The water spread area has increased due to the commissioning of waste water treatment plants (ex. Vidyaranyapura, Rayankere, Kesare) during late 90's and early 2000.

\begin{tabular}{|r|c|r|r|r|}
\hline \multirow{2}{*}{ Year } & \multicolumn{2}{|c|}{ Vegetation } & \multicolumn{2}{c|}{ Non vegetation } \\
\cline { 2 - 5 } & $\%$ & \multicolumn{1}{c|}{ Ha } & \multicolumn{1}{c|}{$\%$} & \multicolumn{1}{c|}{ Ha } \\
\hline 1973 & 51.09 & 10255.554 & 48.81 & 9583.83 \\
\hline 1989 & 57.58 & 34921.69 & 42.42 & 8529.8 \\
\hline 1999 & 44.65 & 8978.2 & 55.35 & 11129.77 \\
\hline 2009 & 09.24 & 1857.92 & 90.76 & 19625.41 \\
\hline
\end{tabular}

TABLE II. TEMPORAL LAND COVER DETAILS.

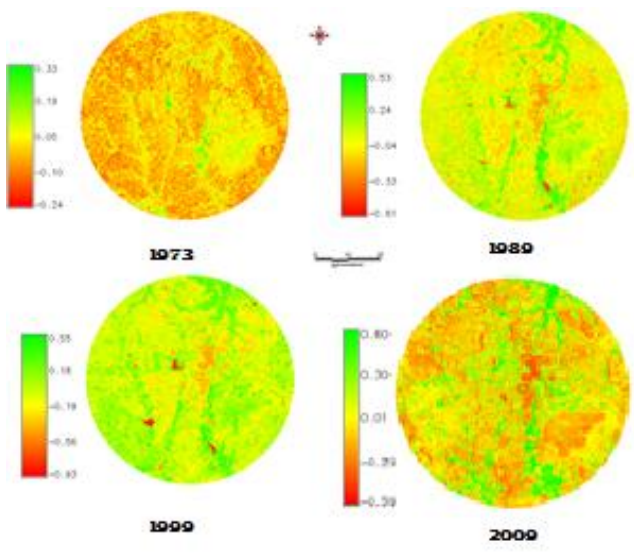

Figure 4. Temporal Land cover changes during 1973 - 2009

2) Built up Density Gradient Analysis: Built up density was minimal and the value ranges from 0.026 (considering $3 \mathrm{~km}$ buffer) to 0.036 (without considering $3 \mathrm{~km}$ buffer) in the North east direction (in 1973). The federal government's policy in 1990's to develop tier 2 cities led to the increase in urban area. There was a sharp growth in the region in almost all direction from 1999 till 2009, maximum value reaching 0.216 in the NE direction (considering $3 \mathrm{~km}$ buffer) and 0.42 (without considering the buffer). This can be attributed to development of this region with the IT \& BT industry which were earlier confined to Bangalore.

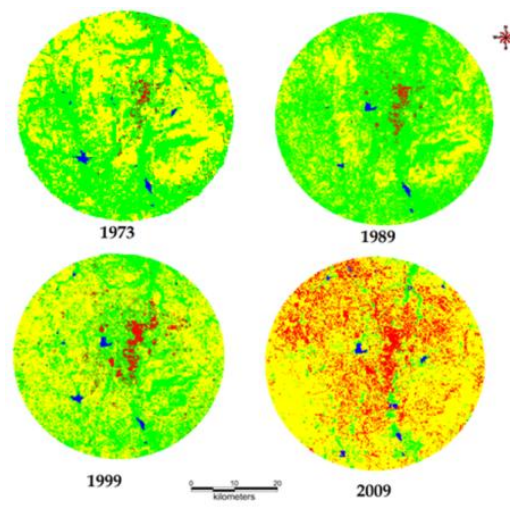

Figure 5. Classification output of Mysore

\begin{tabular}{|l|r|r|r|r|}
\hline $\begin{array}{l}\text { Land } \\
\text { use }\end{array}$ & \multirow{2}{*}{ Urban } & Vegetation & Water & \multirow{2}{*}{ Others } \\
\cline { 1 - 1 } Year & & & & \\
\hline 1973 & 222.93 & 10705.68 & 124.47 & 9054.99 \\
\hline 1989 & 229.41 & 13242.51 & 78.75 & 6557.4 \\
\hline 1999 & 730.8 & 8360.1 & 117.9 & 10899.2 \\
\hline 2009 & 3757.489 & 1159.336 & 142.58 & 15050.5 \\
\hline \multicolumn{5}{|l|}{20108.91} \\
\hline
\end{tabular}

TABLE III. TEMPORAL LAND USE DETAILS FOR MYSORE 


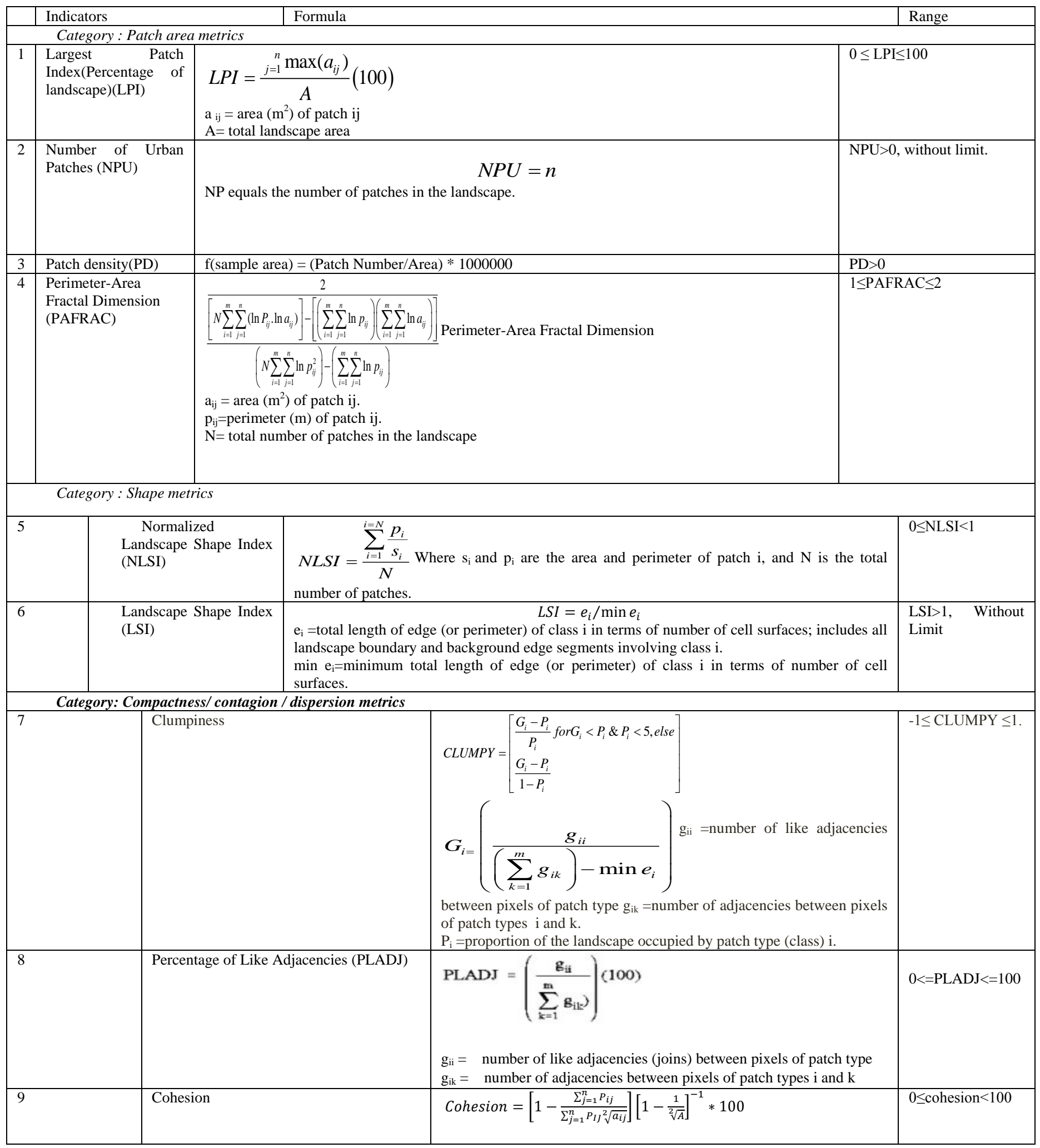




\begin{tabular}{|c|c|c|c|}
\hline 10 & Aggregation index(AI) & $\begin{array}{l}A I=\left[\sum_{i=1}^{m}\left(\frac{g_{i i}}{\max \rightarrow g_{i i}}\right) P_{i}\right](100) \\
\mathrm{g}_{\mathrm{ii}}=\text { number of like adjacencies between pixels of patch type } \\
\mathrm{P}_{\mathrm{i}}=\text { proportion of landscape comprised of patch type. }\end{array}$ & $1 \leq \mathrm{AI} \leq 100$ \\
\hline 11 & Interspersion and Juxtaposition(IJI) & $\begin{array}{l}\boldsymbol{I J I}=\frac{-\sum_{i=1}^{m} \sum_{k=i+1}^{m}\left[\left(\frac{e_{i k}}{E}\right) \cdot \ln \left(\frac{e_{i k}}{E}\right)\right]}{\ln (0.5[m(m-1)])}(\mathbf{1 O O}) \mathrm{e}_{\mathrm{ik}}=\text { total length }(\mathrm{m}) \\
\text { of edge between patch types } \\
\mathrm{E}=\text { total length (m) of edge in landscape, excluding background } \\
\mathrm{m}=\text { number of patch types (classes) present in the landscape. }\end{array}$ & $0 \leq \mathrm{IJI} \leq 100$ \\
\hline
\end{tabular}

TABLE IV. SPATIAL LANDSCAPE INDICES

TABLE V.

\begin{tabular}{|c|c|c|}
\hline Year & $\begin{array}{c}\text { Kappa } \\
\text { coefficient }\end{array}$ & $\begin{array}{c}\text { Overall accuracy } \\
(\%)\end{array}$ \\
\hline 1973 & 0.76 & 75.04 \\
\hline 1989 & 0.72 & 79.52 \\
\hline 1999 & 0.82 & 78.46 \\
\hline 2009 & 0.86 & 84.58 \\
\hline
\end{tabular}

TABLE VI. KAPPA STATISTICS AND OVERALL ACCURACY

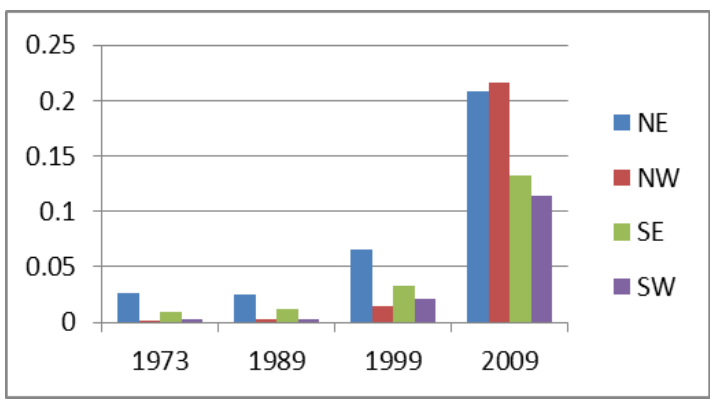

Figure 6. Urban density analysis of Mysore

3) Urban sprawl analysis: Shannon entropy computed using temporal data are listed in Table VI. Mysore is experiencing the sprawl in all directions as entropy values are closer to the threshold value $(\log (8)=0.9)$. Lower entropy values of $0.007(\mathrm{NW}), 0.008(\mathrm{SW})$ during 70's shows an aggregated growth as most of urbanization were concentrated at city centre. However, the region experienced dispersed growth in 90's reaching higher values of $0.452(\mathrm{NE}), 0.441$ (NW) in 2009 during post 2000's.

The entropy computed for the city (without buffer regions) shows the sprawl phenomenon at outskirts. However, entropy values are comparatively lower when buffer region is considered. Shannon's entropy values of recent time confirms of minimal fragmented dispersed urban growth in the city. This also illustrates and establishes the influence of drivers of urbanization in various directions.

\begin{tabular}{|l|l|l|l|l|}
\hline & NE & NW & SE & SW \\
\hline 2009 & 0.452 & 0.441 & 0.346 & 0.305 \\
\hline 1999 & 0.139 & 0.043 & 0.0711 & 0.050 \\
\hline 1992 & 0.060 & 0.010 & 0.0292 & 0.007 \\
\hline 1973 & 0.067 & 0.007 & 0.0265 & 0.008 \\
\hline
\end{tabular}

TABLE VII. SHANNON ENTROPY INDEX

4) Spatial patterns of urbanisation: In order to understand the spatial pattern of urbanization, eleven landscape level metrics were computed zonewise for each circle. These metrics are discussed below: Number of Urban Patch $(\mathrm{Np})$ is a landscape metric indicates the level of fragmentation and ranges from 0 (fragment) to 100 (clumpiness).

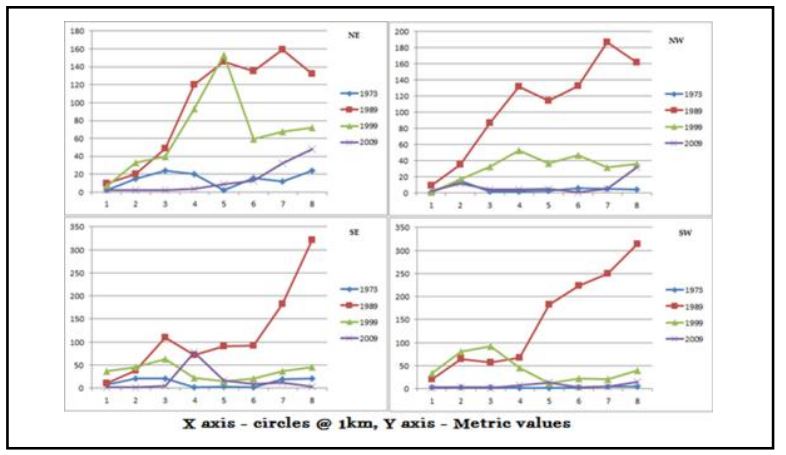

Figure 8.a Number of urban patches (zonewise, circlewise)

Figure 8a illustrates that the city is becoming clumped patch at the center, while outskirts are relatively fragmented. Clumped patches are more prominent in NE and NW directions and patches is agglomerating to a single urban patch. Largest patch index (Fig 8b) highlights that the city's landscape is fragmented in all direction (in 1973) due to heterogeneous landscapes, transformed a homogeneous single patch in 2009.The patch sizes given in figure 8c highlights that there were small urban patches in all directions (till 1999) and the increase in the LPI values implies increased urban patches during 2009 in the NE and SW. Higher values at the center indicates the aggregation at the center and in the verge of 
forming a single urban patch largest patches were found in NE and SW direction (2009).

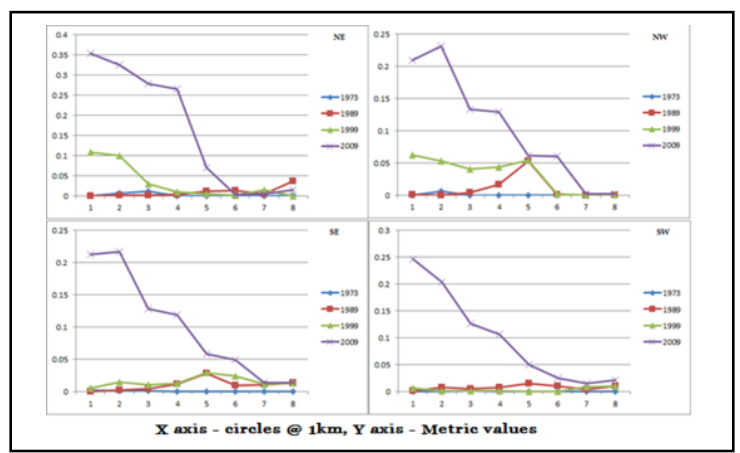

Figure 8.b Largest Patch - zonewise, circlewise

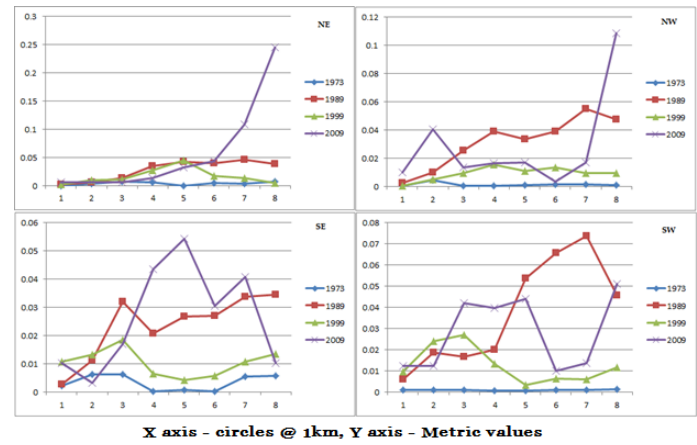

Figure 8.c Patch density - zonewise, circle wise

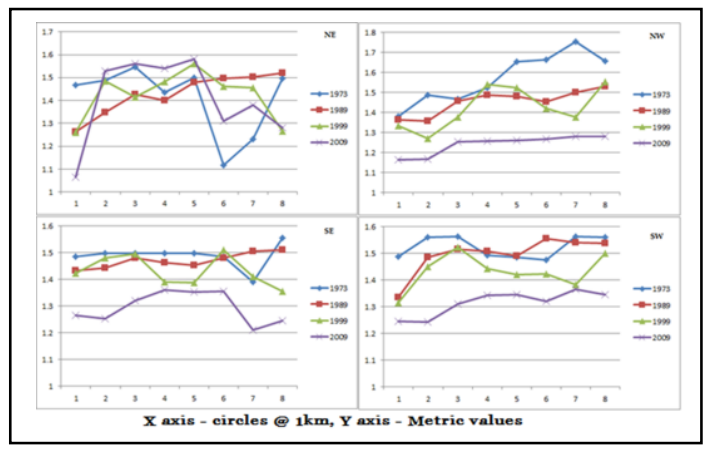

Figure 8.d PAFRAC - zonewise, circle wise

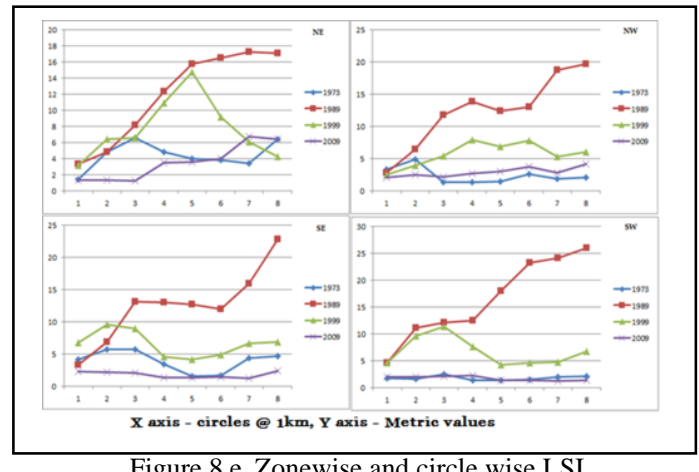

The patch density (Fig 8c) is calculated on a raster map, using a 4 neighbor algorithm. Patch density increases with a greater number of patches within a reference area. Patch density was higher in 1973 as the number of patches is higher in all directions and gradients due to presence of diverse land use, which remarkably increased post 1989(NW) and subsequently reduced in 1999, indicating the sprawl in the region in in early 90's and started to clump during 2009, which was even confirmed by number of patches.

PAFRAC approaches 1 for shapes with very simple perimeters such as squares (indicating clumping of specific classes), and approaches 2 for shapes with highly convoluted, perimeters. PAFRAC requires patches to vary in size. Results (Fig 8d) indicate of dispersed development during 70's and 80 's as PAFRAC highly convoluted. The value approaches 1 in 1990's and 2000's indicating aggregation leading to clumped region of urban land use.

Landscape Shape Index (LSI): LSI equals to 1 when the landscape consists of a single square or maximally compact (i.e., almost square) patch of the corresponding type and LSI increases without limit as the patch type becomes more disaggregated. Results (Fig 8e) indicate that there were low LSI values in 1973 as there was minimal urban areas which were aggregated at the centre. Since 1990's the city has been experiencing dispersed growth in all direction and circles, towards 2009 it shows a aggregating trend as the value reaches 1.Normalized Landscape Shape Index (NLSI): NLSI is 0 when the landscape consists of single square or maximally compact almost square, it increases as patch types becomes increasingly disaggregated and is 1 when the patch type is maximally disaggregated. Results (Fig 8f) indicates that the landscape had a highly fragmented urban class, which became further fragmented during 80 's and started clumping to form a single square in late 90's especially in $\mathrm{NE}$ and $\mathrm{NW}$ direction in all circle and few inner circles in SE and SW directions, conforming with the other landscape metrics.

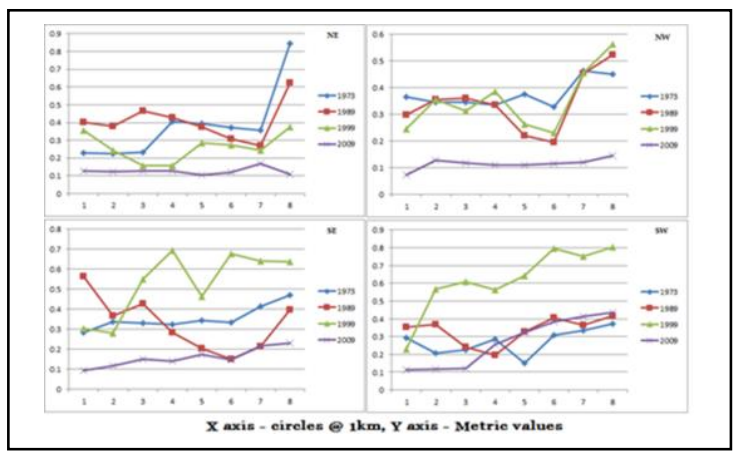

Figure 8.f Zone and circlewise NLSI

Clumpiness index equals 0 when the patches are distributed randomly, and approaches 1 when the patch type is maximally aggregated. Aggregation index equals 0 when the patches are maximally disaggregated and equals 100 when the patches are maximally aggregated into a single compact patch. IJI approaches 0 when distribution of adjacencies among unique patch types becomes increasingly uneven; is equal to 100 when all patch types are equally adjacent to all other patch types.

Clumpiness index, Aggregation index, Interspersion and Juxtaposition Index highlights that the center of the city is more compact in 2009 with more clumpiness and aggregation in NW and NE directions. In 1973 the results indicate that there were a 
small number of urban patches existing in all direction and in every circle and due to which disaggregation is more. Post 1999 and in 2009 it is observed that large urban patches are located closely almost forming a single patch especially at the center and in NW direction in different gradients (Fig 8g, Fig 8h and Fig 8i).

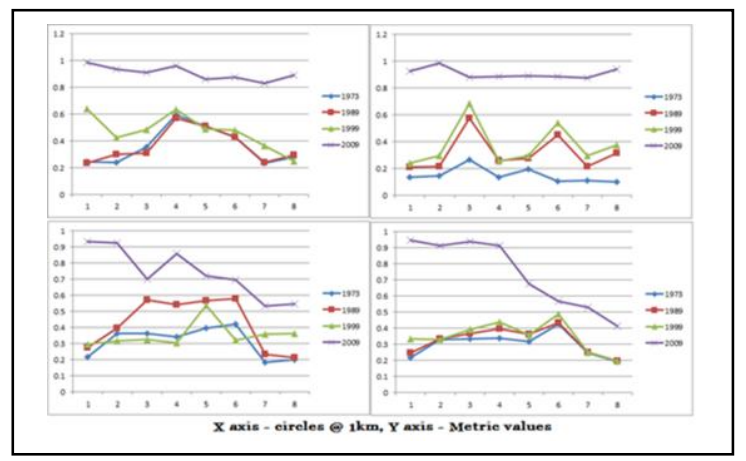

Figure 8.g Clumpiness - zonewise, circle wise

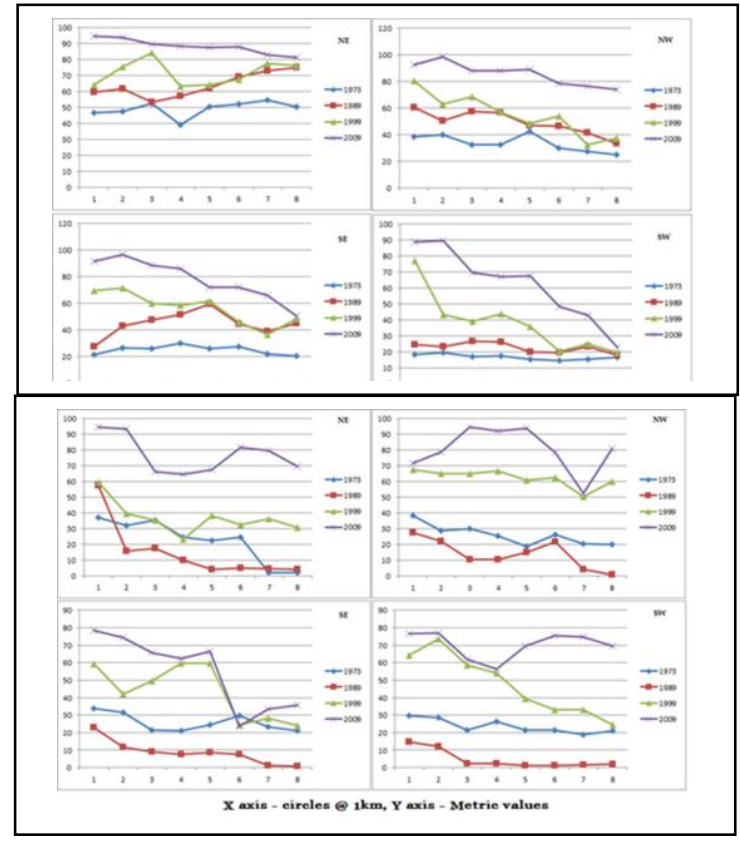

Figure 8.i Zone and circle wise - IJI

Percentage of Like Adjacencies (Pladj) is the percentage of cell adjacencies involving the corresponding patch type those are like adjacent. Cell adjacencies are tallied using the doublecount method in which pixel order is preserved, at least for all internal adjacencies. This metrics also indicates the city center is getting more and more clumped with similar class (Urban) and outskirts are relatively sharing different internal adjacencies.

Patch cohesion index measures the physical connectedness of the corresponding patch type. This is sensitive to the aggregation of the focal class below the percolation threshold. Patch cohesion increases as the patch type becomes more clumped or aggregated in its distribution; hence, more physically connected. Above the percolation threshold, patch cohesion is not sensitive to patch configuration [18]. Figure 8k indicate of physical connectedness of the urban patch with the higher cohesion value (in 2009). Lower values in 1973 illustrate that the patches were rare in the landscape.

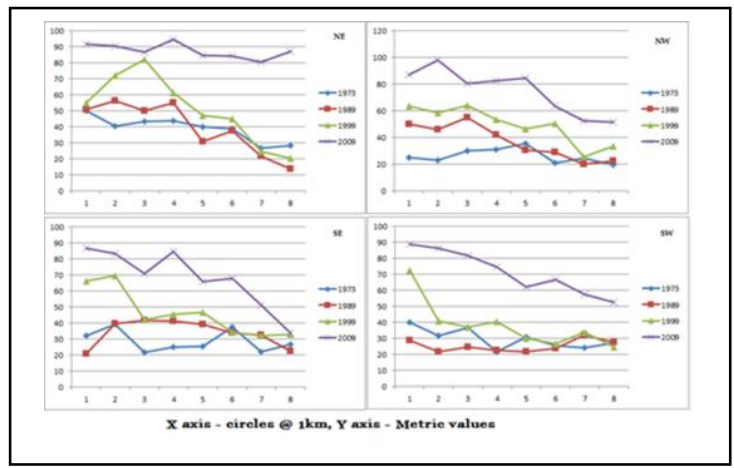

Figure 8.j Zone and circlewise Pladj

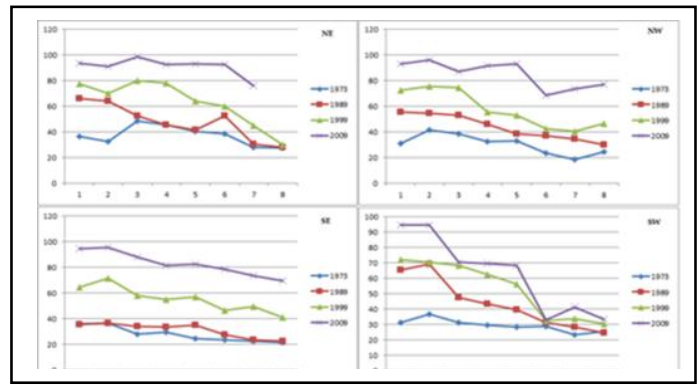

Figure 8.k Cohesion Index

\section{CONCLUSION}

Karnataka government's current focus to develop tier 2 cities in order to decongest major cities, has posed a challenge as unplanned developmental activities is leading to urban sprawl impinging basic amenities to the common man in the outskirts. Availability of spatial data since 1970's has aided in the temporal land use dynamics. Spatial metrics in conjunction with the density gradient approach have been effective in capturing the patterns of urbanization at local levels. The techniques would aid as decision-support tools for unraveling the impacts of classical urban sprawl patterns in Mysore. A set of spatial metrics describing the morphology of unplanned areas have been extracted along with temporal land uses. The extracted indices have indicated the areas of high likelihood of 'unplannedness' considering the three dimensions (size/density/pattern).

Land use assessed for the period 1973 to 2009 using Gaussian maximum likelihood classifier highlight that there has been a significant increase $(514 \%)$ in urban area, with consequent reduction in vegetation cover. Built up density was minimal and the value ranges from 0.026 (considering $3 \mathrm{~km}$ buffer) to 0.036 (without considering $3 \mathrm{~km}$ buffer) in the North east direction (in 1973). Shannon entropy computed using temporal data illustrates that Mysore city is experiencing the sprawl in all directions as entropy values are closer to the threshold. Spatial metrics at landscape level reveal that the landscape had a highly fragmented urban class and started clumping to form a single square in late 90's especially in NE and NW direction in all circle and few inner circles in SE and SW directions, conforming to the other landscape metrics. 
Local urban and rural planners need to put forward effective implementable adaptive plans to improve basic amenities in the sprawl localities. Temporal land use analysis along with urban density gradient across four directions has helped in visualizing the growth along with the cultural and industrial evolution.

\section{ACKNOWLEDGEMENT}

We are grateful to NRDMS Division, The Ministry of Science and Technology (DST), Government of India and Centre for infrastructure, Sustainable Transportation and Urban Planning (CiSTUP), Indian Institute of Science for the financial and infrastructure support.

\section{REFERENCES}

[1] F. Aguilera, R. Talavera. (2009). "Valoración de escenarios futuros a través de la conectividad del Paisaje (Future scenarios assessment through landscape connectivity)." Observatorio Medioambiental 12, pp. 17-36. (in Spanish, abstract version in English)

[2] M. Alberti, P. Waddell. (2000). "An integrated urban development and ecological simulation model.” Int. Assess. 1, pp. 215-227.

[3] N. Batisani, B. Yarnal. (2009). "Urban expansion in Centre County, Pennsylvania: Spatial dynamics and landscape transformations. Applied Geography." 29(2), pp. 235-249.

[4] S. Berling-Wolf, J. Wu. (2004). "Modelling urban landscape dynamics: a case study in Phoenix, USA." Urban Ecosyst. 7, pp. 215-240.

[5] J. Brueckner. (2001). "Urban Sprawl: Lessons from Urban Economics," Unpublished Manuscript, (Department of Economics and Institute of Government and Public Affairs, University of Illinois at UrbanaChampaign, 2000).

[6] M.S. Calvo-Iglesias, U. Fra-Paleo, R.A. Dias-Varela, (2008). "Changes in farming system and population as drivers of land cover and landscape dynamics: the case of enclosed and semi openfield systems in Northern Galicia (Spain)". Landscape \& Urban Plan. 90, pp. 168-177.

[7] R. G. Congalton, (1991). "A review of assessing the accuracy of classifications of remotely sensed data". Remote Sensing of Environment, 37, pp. 35-46.

[8] R. G. Congalton, R. G. Oderwald, \& R. A. Mead, (1983). "Assessing Landsat classification accuracy using discrete multivariate analysis statistical techniques." Photogrammetric Engineering and Remote Sensing, 49, pp. 1671-1678.

[9] N. Currit, W. Easterling, (2009). "Globalization and population drivers of rural-urban land-use change in Chihauhua, Mexico." Land Use Policy, 26, pp. 535-544.

[10] R.O. Duda, P.E. Hart, D.G. Stork, (2000), "Pattern Classification." A Wiley-Interscience Publication, Second Edition, ISBN 9814-12-602-0.

[11] A. Firmino, (1999). "Agriculture and landscape in Portugal". Landscape and Urban Planning. 46, pp. 83-91.

[12] Food and Agriculture Organization, (1995). "Planning for Sustainable Use of Land Resources: Towards a New Approach." Land and Water Development Division, Rome.

[13] Y. Gao, Liu, (2008). "Mapping land degradation from space: A comparative study of Landsat ETM+ and ASTER data." International Journal of Remote Sensing, 29, pp. 4029-4043.

[14] J. Geoghegan, L.A. Wainger, N.E. Bockstael, (1997). "Spatial landscape índices in a hedonic framework: an ecological economics analysis using GIS.” Ecol. Econ. 23, pp. 251-264.

[15] K. Gibert, M. Sànchez-Marrè, (2011). "Outcomes from the iEMSs data mining in the environmental sciences work shop series." Environmental Modelling \& Software, 26 (7), pp. 983 -985.

[16] C. E. Gonzalez-Abraham, V. C. Radeloff, R. B. Hammer, T. J. Hawbaker, S. I. Stewart, \& M. K. Clayton, (2007). "Building patterns and landscape fragmentation in northern Wisconsin, USA." Landscape Ecology, 22, pp. 217-230.
[17] B.H. Green, (1990). "Agricultural intensification and the loss of habitat, species and anemity in British grasslands: a review of historical change and assessment of future prospects." Grass Forage Sci. 45, pp. 365-372.

[18] E.J. Gustafson, (1998). "Quantifying landscape spatial pattern: what is the state of the art?," Ecosystems 1, pp.143-156.

[19] W.B. Harms, A.H.F. Stottelder, W. Vos. (1984). "Effects of intensification of agriculture on nature and landscape in the netherlands." Ekologia (CSSR) 3, pp. 281-304.

[20] M. Herold, J. Scepan, K.C. Clarke, (2002). "The use of remote sensing and landscape metrics to describe structures and changes in urban land uses." Environ. Plann. A 34, pp.1443-1458.

[21] G.D.Jenerette, D. Potere. (2010). "Global analysis and simulation of land-use change associated with urbanization." Landsc. Ecol. 25 (5), pp. 657-670.

[22] G.D. Jenerette, J. Wu, (2001). "Analysis and simulation of land-use change in the Central Arizona - Phoenix region, USA." Landsc. Ecol. 16 , pp. 611-626.

[23] M. Johnson, (2001). "Environmental impacts of urban sprawl: a survey of the literature and proposed research agenda." Environment and Planning A, 33, pp. 717-735.

[24] J. Kubes, (1994). "Bohemian agricultural landscape and villages, 1950 and 1990: Landuse, landcover and other characteristics." Ekologia (Bratislava) 13, pp. 187-198.

[25] A. Lagarias, 2011. "Land use planning for sustainable development in periurban ecosystems: the case of Lake Koroneia in Thessaloniki, Greece. "In Proceedings of the 2nd international exergy, life cycle assessment and sustainability workshop \& symposium, ELCAS 2, Nisyros, Greece.

[26] K.M., Lata, C.H.S. Rao, V.K. Prasad, K.V.S. Badarianth, V. Raghavasamy, (2001). Measuring Urban sprawl A case study of Hyderabad, gis@development, 5(12),pp. 26-29.

[27] Y. Li, S. Zhao, K. Zhao, P. Xie, J. Fang, (2006). "Land-cover changes in an urban lake watershed in a mega-city, central China." Environmental Monitoring and Assessment, 115, pp. 349-359.

[28] X. Li, Q. Yang, X. Liu, (2008). "Discovering and evaluating urban signatures for simulating compact development using cellular automata." Landsc. Urban Plann. 86, pp. 177-186.

[29] T. M. Lillesand, R. W. Kiefer, (2005). "Remote sensing and image interpretation." New York: John Wiley \& Sons.

[30] Z. Lipsky, (1992). "Landscape structure changes in the Czech rural landscape." In: Cultural aspects of landscape. 2nd Int. Con., 1992. IALE, pp. 80-86.

[31] M. Luck, J.G. Wu, (2002). "A gradient analysis of urban landscape pattern: a case study from the Phoenix metropolitan region, Arizona, USA." Landsc. Ecol. 17, pp. 327-339.

[32] U. Mander, H. Palang, (1994). "Change on landscape structure in Estonia during the Soviet period." GeoJournal 33, pp.55-62.

[33] K. McGarigal, B. J. Marks, 1995. "FRAGSTATS: spatial pattern analysis program for quantifying landscape structure." USDA Forest Service General Technical Report PNW-351. www.umass.edu/landeco/research/fragstats/fragstats.html.

[34] J.H.A. Meeus, (1993). "The transformation of agricultural landscapes in Western Europe." The Science of the Total Environment 129. pp. 171-190.

[35] A. Melluma, (1994). "Metamorphoses of Latvian landscapes during fifty years of Soviet rule." GeoJournal 33, pp. 55-62

[36] N. E. Mitrakis, C. A. Topalogou, T. K. Alexandridis, J. B. Theocharis, G. C. Zalidis, (2008). "A novel self organising neuro-fuzzy multilayered classifier for land cover classification of a VHR image." International Journal of Remote Sensing, 29, pp. 4061- 4087.

[37] T. G. Ngigi, R. Tateishi, A. Shalaby, N. Soliman, , M. Ghar, (2008). "Comparison of a new classifier, The mix unmix classifier, with conventional hard and soft classifiers." International Journal of Remote Sensing, 29, pp. $4111-4128$.

[38] S.K. Pathan, J G. Patel, R.J. Bhanderi. Ajai, Kulshrestha, V.P. Goyal, D.L. Banarjee. S. Marthe, V.K. Nagar, V. Katare, (2004). "Urban planning with specific reference to master plan of lndore city using RS and GIS techniques." Proc. of GSDI-7 International Conference on 
Spatial Data Infrastructure tbr Sustainable Development, held at Bangalore from Feb, 2-6, 2004.

[39] M. Pereira dos Santos Silva, G. Camara , M. Sobral I. Escada, R.C. Modesto de Souza, (2008). "Remote sensing image mining: detecting agents of land-use change in tropical forest areas." International Journal of Remote Sensing 29 (16), pp. 4803-4822.

[40] M. Phipps, J. Baudry, F. Burel, (1986). "Dynamique de I'organisation ecologique d'un paysage rural: Modalites de la desorganisation dans une zone peri-urbaine." C.R. Acad. SC. Paris. 303. pp.263268

[41] C. Potter, M. Lobley, (1996). "Unbroken threads? Succession and its effects on family farms in Britain." Sociologia Ruralis 36, pp. 286-306.

[42] T. V. Ramachandra, U. Kumar, (2008). "Wetlands of Greater Bangalore, India: Automatic Delineation through Pattern Classifiers." Electronic Green Journal, Issue 26, Spring 2008 ISSN: 1076-7975.

[43] C. Renetzedera, S. Schindlera, J. Peterseila, M.A. Prinza, S. Mücherc, T. Wrbka, (2010). "Can we measure ecological sustainability? Landscape pattern as an indicator for naturalness and land use intensity at regional, national and European level." Ecol. Indic. 10, pp. 39-48.

[44] J.P. Rossi, I. van Halder, (2010). "Towards indicators of butterfly biodiversity based on a multiscale landscape description." Ecol. Indic. 10, pp. 452-458.

[45] A. Schneider, K.C. Seto, D. Webster, (2005). "Urban growth in Chengdu, Western China: application of remote sensing to assess planning and policy outcomes." Environ. Plann. B 32 (3), pp. 323-345.

[46] K.C. Seto, M. Fragkias, (2005). "Quantifying spatiotemporal patterns of urban land-use change in four cities of China with time series landscape metrics." Landsc. Ecol. 20, pp. 871-888.

[47] Z. Sha, Y. Bai, Y. Xie, M. Yu, L. Zhang, (2008). "Using a hybrid fuzzy classifier (HFC) to map typical grassland vegetation in Xilin River Basin, Inner Mongolia, China." International Journal of Remote Sensing, 29, pp. 2317-2337.

[48] T. Simoniello, M.T. Carone, R. Coppola, A. Grippa, M. Lanfredi, M. Liberti, M. Macchiato, (2006). "Preliminary study to monitor land degradation phenomena through landscape metrics. In: 2nd Workshop of the EARSeL SIG on Land Use and Land Cover." Center for Remote Sensing of Land Surfaces, Bonn, pp. 408 - 414.

[49] H.S. Sudhira, T.V. Ramachandra, K.S. Jagadish, (2004). "Urban sprawl: metrics, dynamics and modelling using G1S." Int. J Applied Earth Observation and Geoinformation,' 5, pp. 29-39.

[50] P. Torrens, M. Alberti, (2000). "Measuring sprawl. CASA working paper series 27.” UCL. http://www.casa.ucl.ac.uk/publications/workingpapers.asp.
[51] P. M. Vitousek, (1994). "Beyond global warming: ecology and global change.” Ecology 75, pp. 1861-1876.

[52] R. Wood, J. Handley, (2001). "Landscape dynamics and the management of change." Landscape Research, 26 (1), pp. 45-54.

[53] X. J. Yu, C.N. Ng, (2007). "Spatial and temporal dynamics of urban sprawl along two urban-rural transects: a case study of Guangzhou, China." Landsc. Urban Plann. 79, pp. 96-109.

[54] Q. Zhang, J. Wang, X. Peng, R. Gang, P. Shi, (2002). "Urban built-up land change detection with road density and spectral information from multi- temporal Landsat TM data." Int. J. Remote Sensing, 23(15), pp. 3057-3078

\section{AUTHORS PROFILE}

Dr. Ramachandra has Ph.D. in energy and environment from Indian Institute of Science. At present, Coordinator of Energy and Wetlands Research Group (EWRG), Convener of Environmental Information System (ENVIS) at Centre for Ecological Sciences (CES), Indian Institute of Science (IISc). He has made significant contributions in the area of energy and environment. His research area includes wetlands, conservation, restoration and management of ecosystems, environmental management, GIS, remote sensing, regional planning and decision support systems. During the past ten years he has established an active school of research in the area of energy and environment. He teaches principles of remote sensing, digital image processing and Natural resources management. He has published over 184 research papers in reputed peer reviewed international and national journals, 118 papers in the international and national symposiums as well as 14 books. In addition, he has delivered a number of plenary lectures at national and international conferences. He is a fellow of Institution of Engineers (India), IEE (UK), Senior member, IEEE (USA) and many similar institutions. Details of his research and copies of publications are available at http://ces.iisc.ernet.in/energy/

http://ces.iisc.ernet.in/grass

Bharath $\mathrm{H}$ Aithal, Electrical and Electronics Engineering graduate from Bangalore University. Currently, he is pursuing Ph.D at Indian Institute of Science. His area of interest are spatial pattern analysis, Urban growth modeling, natural disasters, geoinformatics, landscape modeling and urban planning, open source GIS, digital image processing.

Sreekantha S has M Sc in Remote Sensing and GIS and currently working as project trainee at Energy and Wetlands Research Group (EWRG), CES, IISc. His area of interest are urban sprawl analysis, seismic zonation, remote sensing. 